Fabian Sonnenburg

\title{
The Effects of Airports on Industrial and Commercial Property Development: The Case of Brisbane Airport ${ }^{1}$
}

Within the last three decades, many large airports have experienced high growth rates in passengers handled and freight. As a result, airports have often extended their airside capacities to gain market share. Airside includes all facilities on airport land (within the airport boundaries) which are directly linked to air transport operations such as runways and aprons. In particular, major hub airports have evolved into important nodes for global air transportation networks.

However, growth has recently cooled due to critical events (e.g., terrorist attacks, volcanic eruptions), rendering aviation and the revenues of airport operators more volatile (Graham 109). To spread risk as well as to raise non-aviation revenues and meet the demand for commercial and industrial space, many airport operators have also developed and marketed extensive landside facilities. Landside comprises all facilities on airport land which are not directly linked to airside operations such as car parks, shopping centres and logistics buildings. Often, this expansive strategy is part of an implementation of the airport city business model (Baker and Freestone 151). In recent years, this model has been adopted by many airport operators to promote their visions of airports as multifaceted business enterprises to maximise shareholder value (Jarach 119). Research characterises the model as "the more or less dense cluster of operational, airport-related activities, plus other commercial and business concerns, on and around the airport platform" (Güller and Güller 70). At airports with very limited land reserves on-site, it has increasingly become common for operators to invest off-site to exploit additional revenue sources.

Frequently, local real estate market participants play a key role in the development process. Due to their comprehensive experience in the property business, they have provided support to airport opera-

1 This essay is based on the main findings of the author's MSc thesis (Sonnenburg 2012). 
tors to finance and manage their on-site development projects. Innovative cooperation approaches have been adopted, including ground lease, direct development and shared investment in joint venture development projects (Reiss 290).

In many cases, airport-affine companies from different sectors have started to relocate in spatial proximity to major hub airports. In particular, time-sensitive, inter-regionally or internationally-oriented companies have been attracted due to optimal accessibility and highspeed transportation opportunities (Kasarda 2008:52). Different academic models have conceptualised these developments. With regard to spatial analyses, the aerotropolis (Kasarda 2006:35), the airport corridor (Schaafsma 35) and the airea models (Schlaack 17) are the most advantageous. However, these models cannot explain all the location decisions of companies settled on and around airport land. A considerable number of companies have been attracted by moderate prices and the availability of land and properties rather than the airport's service provision. In addition, land tenure restrictions and the extent of government and community support have been critical factors for relocation processes (Güller and Güller 62-69).

The high attractiveness of airport land and adjacent areas for both airport operators and real estate market participants has had important implications for the dynamics of commercial and industrial submarkets. The interdependencies between market participants, their different spatial orientations and interests, and the overlapping and multidimensionality of submarkets as well as the significant impact of regulations and market interventions have led to a complex structure of effects with various local outcomes (Heeg 77).

The real estate development activities at airports have caused a shift in the spatial patterns of investment in surrounding areas. Many airports have started to compete with traditional areas of office development, such as the Central Business District (CBD), the surrounding fringe areas or suburban centres. In addition to the already established logistics facilities, investments in industrial and commercial facilities have been conducted in areas adjacent to airports. These effects appear particularly worthwhile for all fields of spatial research. 


\section{Methodology}

Geographers commenced studying airport development already in the 1930s. However, it was not until the 1990s that the number of studies on air transport and airports increased dramatically and the scope of topics was expanded (Vowles 13). This article provides detailed empirical analysis for Brisbane Airport, focussing explicitly on the effects on industrial and commercial real estate development. This airport has been chosen as a case study because of:

- its extensive land reserves for non-aeronautical developments (the largest in Australia);

- the strong desire of the operator to market land and develop properties;

- the strong preference of the operator for implementation of an airport city strategy;

- and the fast growth of both the population and economy in Brisbane and the region of South East Queensland.

There is good availability of statistical data on property development in Australia. The Australian Bureau of Statistics (ABS) publishes a monthly building approvals survey. It collects and aggregates the estimated value of buildings after completion which is specified by the applicants. The technical term for this value is "non-residential building value approved" (NRBVA). It is considered the best indicator for the activities of the building industry in Australia (OESR 1) and is available on a Statistical Local Area basis. Within capital city areas, a Statistical Local Area normally includes one or a few suburbs. Therefore, it is possible to measure spatial patterns of property investment on a small scale.

This study rests on quantitative and qualitative analyses, partly based on fieldwork in Australia. Five semi-structured, qualitative expert interviews with professionals were undertaken to prepare the cartographic and long-term time series analyses of the building approvals survey. In addition, the following methods were applied: mapping and analysis of land use data and planning documents, interpretation of maps and satellite images, and two background discussions with local researchers. As for the research strategy of triangulation, the results were synthesised to achieve a high degree of detail and causality. 


\section{Development of Brisbane Airport}

Air transportation in Australia has experienced strong growth over the last decades. It has mainly been driven by the deregulation of the airline industry, the increase in international tourism, the concentration of both population and activity in the capital city metropolitan areas and the trends towards service-related and high-value export products. Brisbane Airport has been able to profit disproportionally from the rising number of passengers and the amount of air cargo, owing to its location within South East Queensland. In terms of population and economic growth, this is one of the fastest growing regions in Australia. Over the last three decades, it has experienced several major extensions of its airside capacity. The most important step within this process was the replacement of the old airport by the current international airport. The latter was built close to the old site and commenced operations in 1988. As air traffic continued to grow in the 1990s and 2000s, the construction of a new parallel runway has recently started. In 2011-12, approximately 20 million passengers arrived at and departed from Brisbane Airport (BITRE 90). In international terms, it is a mid-sized but fast-growing airport.

Over the last thirty years, the commercial orientation of Brisbane Airport's operators has changed significantly. Until its privatisation in 1997, both airport operators (the Department of Aviation and the Federal Airports Corporation) developed only a few new landside facilities. After privatisation, the airport saw a considerable amount of non-aviation-related property development by the Brisbane Airport Corporation (BAC). The landside expansion activities peaked in the mid-2000s and dropped recently when the financial crisis caused serious uncertainties in both the aviation and financial markets (BAC 2003:7-8; 2009a:14; 2009b:11). In 2005, BAC dedicated more than one third of its extensive land reserves to non-aeronautical land use. In comparison to the other major Australian airports, this was the highest proportion (Freestone et al. 501; Stevens and Walker 4).

Private real estate developers and institutional investors participated in the development process by reaching a variety of cooperation agreements with BAC, including the release of unapproved land or fully-serviced sites, the building and leasing of a complete facility and sharing the risks in a joint partnering approach. The type of co- 
operation depended on the type of facility (Interviewee 2). An example of a successful cooperation project was the development of a new hotel at the Airport Village (see Figure 1). It met a shortage of available hotel rooms in Brisbane, complemented the offerings of existing hotels and was, therefore, welcomed by planning authorities (Interviewee 4). In spite of the successful conduct of development projects at the airport, BAC was not active as an off-site developer (Interviewee 2).

Car parking charges contribute significantly to the non-aviation revenues of BAC. Its extensive car parking opportunities were a competitive advantage compared to other business locations in Brisbane. However, the charges for car parking at Brisbane Airport were relatively high. Therefore, some competitors developed car parking facilities off-site at the airport entrance to take advantage of the price differential. These companies offer shuttle services to the terminals. In addition, taxi companies also benefit (Interviewee 2, 3).

BAC has played a key role as a landholder (the biggest in Brisbane) and property developer. However, the scope of development on airport land was limited by several factors such as the inability of BAC to sell the land (only leasing is possible) or relatively high leasing rates and rents in comparison to other suburban locations. In 2011, BAC expected to develop $50-70 \%$ of its land by 2030 to avoid flooding the market and a decrease in property prices (Interviewee 2 ). Therefore, general developments on the demand side of the real estate market had a strong impact on the speed of delivery of properties onto the market.

Property development at Brisbane Airport was a crucial requirement for economic growth. In 2008, Brisbane Airport contributed A\$3.2 billion in output to South East Queensland's economy; $A \$ 1.4$ billion spending in the wider community; $A \$ 840$ million in total wages for people employed on airport land; and 16,000 full-time equivalent jobs. By 2029, the number of jobs on-site is estimated to rise to more than 50,000 (BAC 2009b:49). 




Figure 1: ATC precinct interactive map (ATC 2011d).

The business activities at Brisbane Airport were closely connected to those within the adjoining Australia TradeCoast region (ATC region) (see Figure 1). It includes the airport, the sea port and various commercial and industrial precincts in spatial proximity. In addition, it is connected to the south arterial road and the important Gateway Motorway. Due to the spatial proximity to Brisbane, there was suffi- 
cient access to skilled employees and a relatively low cost base compared to other sites in Southeast Queensland.

The region was marketed by Australia TradeCoast (ATC), an agency for business promotion. It was founded in 1999 by BAC, Brisbane City Council (BCC), Port of Brisbane Pty Ltd and Queensland State Government. ATC's objective is to increase the economic value of the region by attracting and retaining investments, promoting the region, and coordinating long-term land use and infrastructure planning (ATC 2011b).

\section{Spatial and Temporal Patterns of Real Estate Development}

The local government area of Brisbane was chosen for the spatial analysis. Its closest border is more than 10 kilometres away from the ATC region. Thus, all airport-related developments were expected to be found within the local government area. To provide an analytical structure for the quantitative analysis, several regions were demarked by analysing spatial patterns of land use and nonresidential property development. The results of the spatial analysis show that Inner Brisbane, the ATC region and the Southwest Corridor were foci of non-residential property development (see Figure 2).

A comparative time series analysis for the ATC region and the Southwest Corridor was conducted to analyse the correlation between the commercial orientation and the amount of NRBVA within the ATC region. The period of interest was divided into three distinct phases:

1. before the construction of the new airport (1980/81 to 1986/ 87)

2. immediately after the opening of the new airport (1987/88 to 1996/97) and

3. after privatisation (1997/98 to $2010 / 11$ ) 


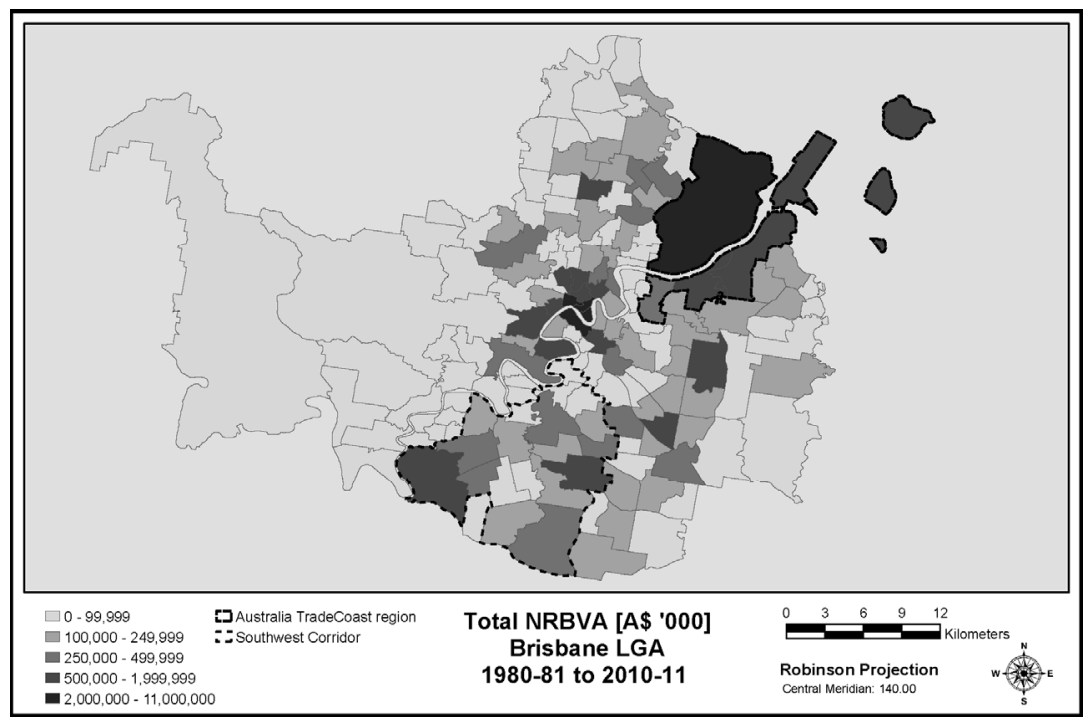

Figure 2: Total NRBVA [A\$ '000], Brisbane Local Government Area, 198081 to 2010-11; own illustration based on data from ABS (2011a, 2011b).

Both time series are shown in Figure 3. In the first phase (1980/81 to $1986 / 87$ ), the NRBVA in both regions fluctuated at a relatively low level. This was mainly because both regions were characterised by industrial land use and by the circumstance that the tertiarisation of the urban economy caused a relatively low demand for industrial properties. Within the first phase, the focus of non-residential property development was mainly on the CBD and the inner city suburbs (Stimson and Taylor 208). 


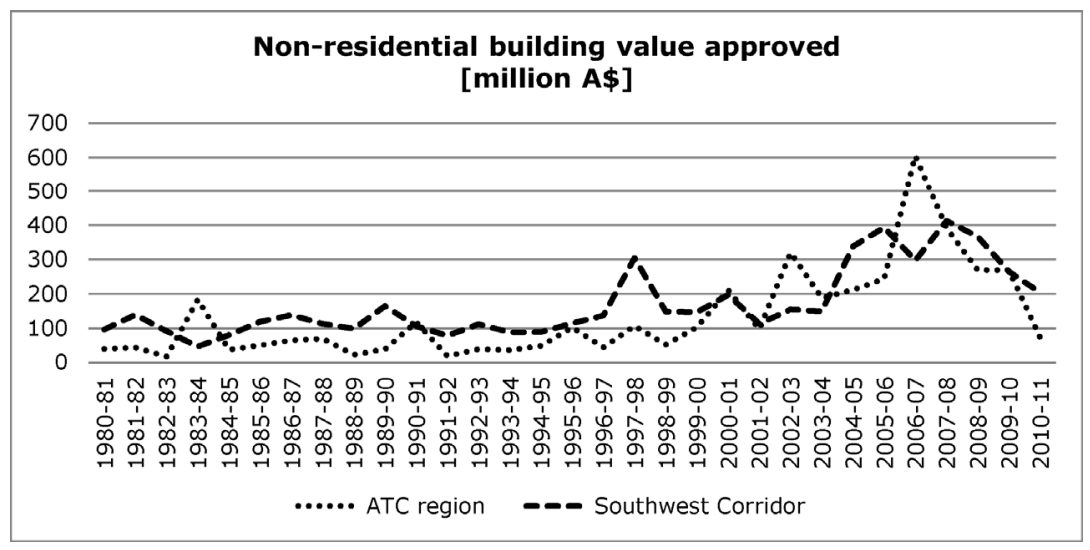

Figure 3: NRBVA, ATC region and Southwest Corridor; own illustration based on data from ABS (2011a, 2011b).

According to the comparison of both time series, the small existing airport did not cause disproportionate growth effects in the ATC region. A second reason for the relatively low NRBVA was the construction of the new airport in the second half of the 1980s. The construction site covered a large amount of the existing land reserves. Accordingly, this land was not available for potential property development in the ATC region.

\begin{tabular}{llll}
\hline Region & $1980-81$ to & $1987-88$ to & $1997-98$ to \\
& $1986-87$ & $1996-97$ & $2010-11$ \\
\hline ATC region & 436,156 & 376,241 & $1,569,469$ \\
Southwest Corridor & 710,345 & 769,829 & $1,744,755$ \\
\hline
\end{tabular}

Table 1: NRBVA, ATC region and Southwest Corridor [A $\$$ '000]; source: own illustration based on data from ABS (2011b).

Table 1 illustrates that the level of investment in the Southwest Corridor was considerably higher than in the ATC region in the first phase. Obviously, the greenfield sites in the Southwest Corridor were more attractive for developers than the established precincts around the airport. These industrial precincts also had access to the regional road network and interstate rail (BCC 1998:vi; 2000:2021). 
In comparison to the first period, the second phase (1987/88-1996/ 97) was characterised by a moderate decrease of NRBVA in the ATC region and a slight increase in the Southwest Corridor (see Table 1). The latter was driven by the ongoing suburbanisation of manufacturing companies from inner city suburbs to main growth corridors along major traffic arteries. These companies mainly produced for the local market to meet the increasing demand of the growing population (Stimson and Taylor 208). In contrast, the relative loss of NRBVA in the ATC region indicates that the opening of the new airport did not immediately attract additional property investments. However, major developments by the Federal Airports Corporation at the airport were the building of several logistics facilities as well as car rental and parking facilities in spatial proximity to the domestic terminal (BAC 2009b:151).

The relative stability of the level of NRBVA in both regions was a common phenomenon of the 1990s and not due to specific conditions. The boom of the late 1980s had produced a huge amount of office space. Vacancy rates were high and it took several years until investment activity started to recover. The first sign of market recovery was the increase in the average take-up rate for industrial land in the ATC region. From 1981 to 1996 , the value rose from 15.9 to 30.8 hectares per annum (BCC 1998:14). This increase indicated a rising demand for industrial land.

Since a privately managed airport is more likely to develop extensive landside facilities, this study expected to find a significant increase in property investment in the ATC region after the privatisation of Brisbane Airport. Accordingly, in the third phase (1997/98 to 2010/11), the level of NRBVA dramatically increased in both regions. This is mainly because Brisbane's office and industrial property markets experienced a long-lasting boom in the 2000s. Figure 4 shows the development of the vacancy rate in Brisbane's CBD office market. The vacancy rate is an adequate indicator for the general market trend in the office property market. As Figure 4 shows, the vacancy rate dropped steadily from 2001, being at its lowest level in 2007. Finally, the increase was halted by the negative impact of the world economic crisis in 2008 and 2009. However, this market bust was only short-term as in 2010 market forecasts already predicted a recovery of the market for 2011 . The industrial property market evinced a similar cyclical development (Jones Lang LaSalle 23, 28). 


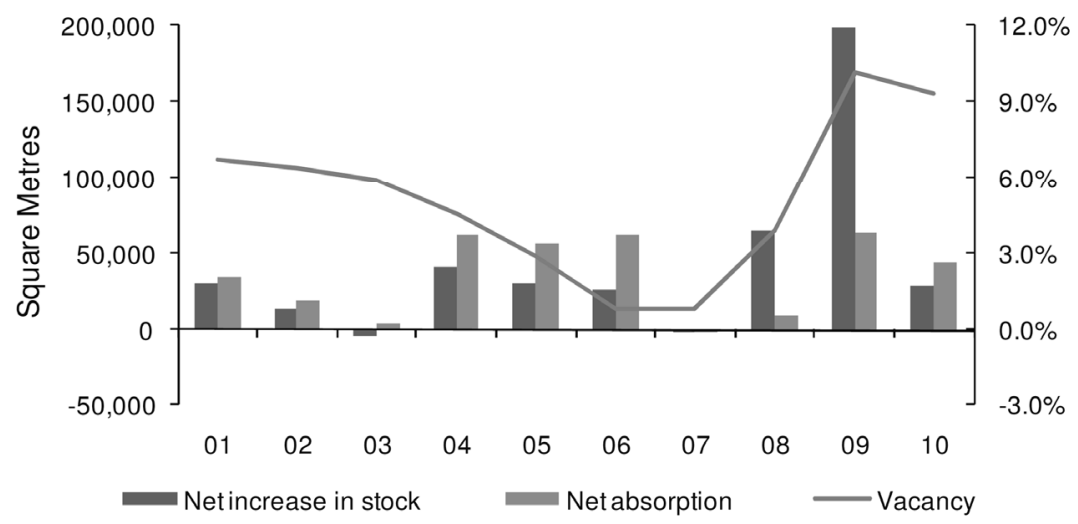

Figure 4: Brisbane CBD office property market - market balance (Jones Lang LaSalle 2011: 23).

This time series analysis shows that the general fluctuation of NRBVA in both regions was strongly influenced by general market dynamics. The extensive growth of landside facilities at Brisbane Airport contributed significantly to the perceptible increase in NRBVA in the third phase, even if the development boom itself must be interpreted as a result of favourable market conditions during the 2000s.

\section{Property and Economic Development within the ATC Region}

To gain a deeper understanding of the airport's effects on development within the ATC region, various small-scale analyses were carried out. These were mainly based on a comparative satellite image interpretation of two Google Earth pictures from 2001 and 2009 as well as five expert interviews. The core areas of new industrial and commercial property development within that period were the following precincts (see Figure 1): the Airport Village, Export Park, Da Vinci Centre, TradeCoast Central, the area between Port North and the Brisbane River and the Myrtletown Precinct. Each precinct of the region is characterised by an individual mix of properties and functions. The Airport Village, Export Park and Da Vinci Centre are all located at Brisbane Airport. They include a variety of different industrial and commercial facilities. The Direct Factory Outlet at Airport Village is the dominating retail facility. The Export Park is char- 
acterised by a high concentration of logistics companies, such as local subsidiaries of DB Schenker, Qantas Freight and Fedex. The Da Vinci Centre is divided into a logistics-oriented part with immediate airside access and an area including aviation educational facilities. TradeCoast Central is the old airport site which was originally owned by the Federal Government and later gifted to the BCC. It is currently owned and developed by 'TradeCoast Central', a development company and major competitor of BAC on the property market. The area contains 135 hectares of land and was a "fully integrated master planned corporate office park and industrial community" (ATC 2011c). The area between Port North and the Brisbane River is developed as a relief area for port infrastructure, for example, the storage of bulk commodities or the handling of import-export cargo. The Myrtletown Precinct is a general industrial area. As it is very close to the airport, building height is restricted by the authorities to protect the airspace for arriving and departing aircraft (Interviewee $1)$.

The long-term establishment of many manufacturing companies has led to both advantages of localisation and urbanisation within the ATC region. Aviation, marine and manufacturing companies created local networks to increase efficiency. These advantages of agglomeration promoted the settlement of further companies from different sectors. Whereas the area has ever since been a strong manufacturing base, comprising petroleum, food and beverage industries, the share of service-oriented transport, logistics, and warehousing companies have significantly increased in recent years (Interviewee 1). In 2011, the number of service-related businesses in the ATC region was already slightly higher than that of manufacturing, wholesaling, storage, supply and production (Daoud and O'Sullivan 11). Accordingly, the demand for office space increased significantly.

In 2011, 184 businesses based within the ATC region were planning to relocate in the course of the next three years (ATC 2011a:1), with $61 \%$ of these companies intending to remain within the ATC region. There were basically three reasons for the relocation decisions: the need for a larger site, changing requirements regarding the technical configuration of their buildings and a strong increase in land and property prices. The latter was significant in Eagle Farm and the suburb of Colmslie and was caused mainly by high property demand and nearby infrastructure upgrades. This led to a displacement pro- 
cess of companies which did not necessarily need fast access to the airport (Interviewee 1, Interviewee 5).

The main result of the small-scale analysis is that the competitive advantages of the ATC region (for example, airport proximity), land and property prices as well as land availability were crucial factors for the location decisions of companies and, in a second step, for the spatial patterns of their property demand.

\section{The Impact of Local Planning and State Transport Authorities}

A critical factor for economic and property development is the planning framework. Both the Queensland Government and Brisbane City Council released mandatory planning schemes. On the one hand, property market participants made their location decisions within these constraints. Industrial and commercial activities were restricted to areas which can be serviced by transport rather than areas where large plots of land are randomly owned. On the other hand, the ATC region was promoted as the main initiator of economic development in the future.

Growth in the ATC region was supported by infrastructure investments from different levels of government. There were several key infrastructure projects, enhancing the accessibility of the ATC region significantly: in March 2010, a new tunnel under the Brisbane River opened (Clem Jones Tunnel). It linked several major roads north and south of the river. Moreover, the A\$2.12 billion 'Gateway Upgrade Project' was completed in 2011 which included several major road infrastructure projects. In addition, the 'Airport Link Project' was finished in 2012 (Queensland Government 2010:6-28). It included a 6.7 kilometre tunnel, directly connecting Brisbane's CBD with the northern suburbs and the airport. Combined with the 'Airport Roundabout Upgrade' at the airport entrance and several smaller projects within the same area, it was the largest infrastructure project in Australia in 2012 (Department of Infrastructure and Planning 71). Due to the steadily increasing workforce, the region experienced an improvement in public transport infrastructure such as trains, on-airport shuttle systems and public buses (Interviewee 2). 


\section{The Impact of the Commonwealth Government}

In Australia, airport development is regulated by the Federal Government. It passed and implemented the Airports Act 1996. Airport land is leased by airport corporations from the Commonwealth but remains federal territory because airports are critical national assets. There is an obligation for airport operators to prepare a draft airport master plan which can be commented on by airport stakeholders. This plan is the basis for all developments on airport land and has to be approved by the Minister for Infrastructure and Transport (Australian Government 1996a:70). Moreover, major development plans are required for significant developments at airports. These plans also need to be publicly commented on (Australian Government 1996a:84). Accordingly, the Department of Infrastructure, Transport, Regional Development and Local Government (2007) has published Airport Development Consultation Guidelines to promote a shared understanding of consultation management. In addition, all building activities at airport sites need to be approved by an airport building controller and be certified as complying with the 'Airports (Building Control) Regulations 1996' (Australian Government 1996b: 96).

This legal situation has been criticized extensively by different airport stakeholders. Ongoing concerns on the local level, such as noise exposure in residential areas or the amount of general commercial development on the airport site were not "effectively integrated into state local decision-making machinery" (Freestone 116). As a result, the concerns expressed by state governments, local councils, community groups, industry and professional associations about commercial developments on airport land were mainly ignored or were at least not crucial to the Federal Government's decisions (Freestone 115; Stevens et al. 279). This situation is not expected to change in the foreseeable future: the Australian Government has recently emphasised that "there will be no substantial review of the Airports Act to accommodate reciprocal output" (Stevens and Walker 2). Therefore, the input of local stakeholders will remain as external comments, rather than real cooperation (ibid.). Freestone interpreted the outcome of airport governance in Australia as the manifestation of a "neoliberal urbanism" (Freestone 123). The results were profitable for the private sector but reduce "total network efficiency" (Searle 111). 


\section{Critical Reflections on the Effects on Property Development}

Airport development does not only produce socially desirable outcomes. Freestone et al. (2006:503) expressed various concerns about the development of non-aeronautical facilities at Australian airports. Firstly, they criticised that the lower number of planning controls for on-site developments is an unfair competitive advantage for the airport operator compared to regular real estate developers. In addition, documentation requirements for landside developments were lower than for off-site developments. Secondly, the diversification of use and the concentration of employment led to the emergence of Australian airports as new urban centres isolated from local planning policies. Thirdly, employment growth caused additional traffic and further needs for public traffic infrastructure investment. There were no legally required contributions to the upgrade costs by airport operators or involved private developers. Fourthly, the rules for land use and consultation of the Airports Act 1996 were insufficient. Airport operators strategically prepare Master Plans which contain different broad scenarios to maximise the variety of consistent future developments. Moreover, they were able to split large projects into several smaller segments to avoid exceeding the $A \$ 10$ million threshold for the preparation of Major Development Plans. This ultimately subverted the opportunities for critical comments by airport stakeholders (Freestone and Baker 267; Freestone et al. 504-505). These aspects can be interpreted as additional incentives for the private sector to participate in the property development activities on airport land.

To avoid costly conflicts, all development stakeholders have established informal consultation processes (Stevens and Walker 2). However, amicable arrangements have sometimes not been successful in resolving conflict. As for the problematic non-consideration of stakeholder interests by the Federal Government, there was one major legal action by the major shopping centre operating business Westfield Management Ltd against BAC with regard to the intended development of the Direct Factory Outlet at Brisbane Airport in 2003. Westfield argued that the project would contravene the Major Development Plan related to land use, planning and building controls determinations of the Airports Act 1996. However, the Federal Court of Australia ultimately confirmed the right of BAC to develop largescale non-aviation projects in 2005 . Until today, this court case is 
deemed a precedent in Australia (Stevens et al. 278; Freestone et al. 505).

\section{Conclusion}

Brisbane Airport is a good example of a medium-sized, fast-growing airport. The liberal regulation by the Federal Government and the huge land reserves offered BAC unique opportunities for on-site industrial and commercial property development. BAC has taken advantage of this situation by realising its airport city vision and marketing its land. It became active as a de-facto real estate developer and established different cooperation arrangements with local property market participants and international investors.

The engagement by BAC has had manifold small-scale effects on the development of surrounding areas. The ATC region has been one of the core areas of industrial and commercial property development in the last three decades. Today, it is characterised by a high concentration of companies and employment opportunities and is also promoted and marketed by BCC, the Queensland Government and Australia TradeCoast. Therefore, it is very likely that the region will experience further growth. The locations of airport-affine companies, serving the needs of the local economy, are concentrated in the industrial areas in immediate spatial proximity to the airport entrance.

A comparison of NRBVA with the Southwest Corridor and the ATC region in different periods showed that the regions grew moderately during the 1980s and 1990s and experienced strong growth in the last decade. This was mainly due to the general trend towards tertiarisation in the 1980s, a significant deterioration of general property market conditions in the 1990s and a common improvement of both property market and general economic conditions in the 2000 s. Due to these macroeconomic developments, the time series analyses could not establish to what extent privatisation of the airport and the following property development by BAC promoted further development within the ATC region in comparison to other areas in Brisbane.

In addition, the strength of airport-related activities of each individual company in the region has remained unknown. Whereas interviewees have reported some cases of strong airport affinity, other 
factors have often been more important for the location choice of companies.

The main finding of this study is that in spite of strong international trends towards the development of extensive landside facilities, local conditions have remained very important for property development around Brisbane Airport. The effects on the local property markets in Brisbane have been dominated by land availability in the airport surroundings, the prices of existing properties and land in spatial proximity to the airport, infrastructure capacities for both private and public transport and the local planning schemes of Brisbane City Council and the Queensland Government. In addition, the strong segmentation of real estate markets and submarket-specific property cycles have played an important role. Further research is required to provide profound empirical evidence on the quantity and quality of airport-induced effects on property development.

\section{List of abbreviations}

ABS - Australian Bureau of Statistics

ATC - Australia TradeCoast

BAC - Brisbane Airport Corporation

BCC - Brisbane City Council

BITRE - Bureau of Infrastructure, Transport and Regional Economics CBD - Central Business District

NRBVA - non-residential building value approved

OESR - Office of Economic and Statistical Research

\section{Bibliography}

ABS, 2011a. 1350.0 - Australian Economic Indicators, Dec 2011. Canberra: Australian Bureau of Statistics. http://www.abs.gov. au/AUSSTATS/abs@.nsf/DetailsPage/1350.0Dec\%202011?Open Document, 2013-01-30.

ABS, 2011b. 8731.0 - Building Approvals, Australia, October 2011. Canberra: Australian Bureau of Statistics. http://www.abs.gov. 
au/Ausstats/abs@.nsf/0/D564DD8D17DAC974CA2573E500152

221?OpenDocument, 2013-01-30.

Australian Government, 1996a. Airports Act 1996. Canberra: Australian Government.

Australian Government, 1996b. Airports (Building Control) Regulations 1996. Canberra, Australian Government

ATC, 2011a. ATC Business Occupant Survey. Brisbane: Australia TradeCoast. hentre/downloads, 2013-01-30.

ATC, 2011b. Australia TradeCoast - Our Role. Brisbane: Australia TradeCoast. http://www.australiatradecoast.com.au/our-role/, 2013-01-30.

ATC, 2011c. Australia TradeCoast Precincts. Brisbane: Australia TradeCoast. http://www.australiatradecoast.com.au/the-region/ atc-precincts/\#Precint $\backslash \% 2011 \backslash \% 20 \backslash \%$ E2 $\ \% 80 \backslash \% 93 \backslash \% 20 T$ rade Coast $\backslash \% 20$ Central, 2013-01-30.

ATC, 2011d. Precinct Interactive Map. Brisbane: Australia Trade Coast. http://www.australiatradecoast.com.au/interactive-precinct -map/, 2013-01-30.

BAC, 2003. Master Plan. Brisbane: Brisbane Airport Cooperation.

BAC, 2009a. BAC Holding Limited Annual Report. Brisbane: Brisbane Airport Cooperation.

BAC, 2009b. Master Plan. Brisbane: Brisbane Airport Cooperation.

Baker, Douglas C., and R. Freestone, 2010. "The Airport City: A New Business Model for Airport Development", in: Macário, Rosario, Van de Voorde, Eddy, eds., Critical Issues in Air Transport Economics and Business. Routledge Studies in the Modern World Economy. New York: Routledge, 150-164.

BCC, 1998. The Brisbane Industrial Land Study. Brisbane: Brisbane City Council.

BCC, 2000. City Plan 2000. Brisbane: Brisbane City Council.

BITRE, 2012. Australian Infrastructure Statistics Yearbook 2012. Canberra: Bureau of Infrastructure, Transport and Regional Economics. http://www.bitre.gov.au/publications/2012/files/stats_ 002.pdf, 2013-01-30.

Daoud, Meredith, and Josh O'Sullivan, 2011. Australia TradeCoast Region Report: Draft Report. Brisbane: Colmar Brunton.

Department of Infrastructure and Planning, 2010. Annual Report 2009-2010. Brisbane, Department of Infrastructure and Planning. 
Department of Infrastructure, Transport, Regional Development and Local Government, 2007. Airport Development Consultation Guidelines. Canberra: Department of Infrastructure, Transport, Regional Development and Local Government.

Freestone, Robert, 2011. "Managing Neoliberal Urban Spaces: Commercial Property Development at Australian Airports". Geographical Research 49(2), 115-131.

Freestone, Robert, and Douglas C. Baker, 2010. "Challenges in Land Use Planning around Australian Airports". Journal of Air Transport Management 16(5), 264-271.

Freestone, Robert, Peter Williams, and Aaron Bowden, 2006. "Fly Buy Cities: Some Planning Aspects of Airport Privatisation in Australia". Urban Policy and Research 24(4), 491-508.

Graham, A., 2009. "How Important are Commercial Revenues to Today's Airports?". Journal of Air Transport Management 15(3), 106-111.

Güller, Mathis, and Michael Güller, 2003. From Airport to Airport City. Barcelona: Gustavo Gili.

Heeg, Susanne, 2009. "Von der Old Downtown zur New Downtown: Das Beispiel der South Boston Waterfront in Boston". Geographische Zeitschrift 97(2-3), 77-94.

Jarach, David, 2001. "The Evolution of Airport Management Practices: Towards a Multi-point, Multi-service, Marketing-driven Firm". Journal of Air Transport Management 7(2), 119-125.

Jones Lang LaSalle, 2011. Northshore Hamilton: Market Research Report and Development Strategy. Brisbane: Jones Lang LaSalle.

Kasarda, John D., 2006. "Airport Cities and the Aerotropolis". The Next American City 10, 35-37.

Kasarda, John D., 2008. "Shopping in the Airport City and Aerotropolis: New Retail Destinations in the Aviation Century". Research Review 15(2), 50-56.

OESR, 2011. Building Approvals. Brisbane: Office of Economic and Statistical Research. http://www.oesr.qld.gov.au/products/ briefs/building-approvals/index.php, 2013-01-30.

Queensland Government, 2010. South East Queensland Infrastructure Plan and Program 2010-2031. Brisbane: Queensland Government. http://www.dsdip.qld.gov.au/resources/plan/SEQIPP/ seqipp-introduction.pdf, 2013-01-30.

Reiss, Brett, 2007. "Maximising Non-Aviation Revenue for Airports: Developing Airport Cities to Optimise Real Estate and Capitalise 
on Land Development Opportunities". Journal of Airport Management 1(3), 284-293.

Schaafsma, Maurits, 2003. "Airports and Cities in Networks". disP The Planning Review 154(3), 28-36.

Schlaack, Johanna, 2010. "Defining the Airea: Evaluating Urban Output and Forms of Interaction Between Airport and Region", in: Knippenberger, Ute, Wall, Alex, eds., Airports in Cities and Regions: Research and Practice. Karlsruhe: KIT Scientific Publishing, 113-125.

Searle, Glen, 1999. "New Roads, New Rail Lines, New Profits: Privatisation and Sydney's Recent Transport Development". Urban Policy and Research 17(2), 111-121.

Sonnenburg, Fabian, 2012. The Effects of Airport Development on Local Real Estate Markets: Quantitative and Qualitative Analyses for Brisbane/Australia. Unpublished diploma thesis (equivalent to MSc). Cologne: University of Cologne.

Stevens, Nicholas J., Douglas C. Baker, and Robert Freestone, 2010. "Airports in their Urban Settings: Towards a Conceptual Model of Interfaces in the Australian Context". Journal of Transport Geography 18(2), 276-284.

Stevens, Nicholas J., and Arron R. Walker, 2009. "Land Use at Privatized Australian Airports: Classification and Analyses". Aerlines 44, 1-5.

Stimson, Robert. J., and Shane P. Taylor, 1998. "Dynamics of Brisbane's Inner City Suburbs". Australian Planner 35(4), 205-214.

Vowles, Timothy M., 2006. "Geographic Perspectives of Air Transportation". Professional Geographer 58(1), 12-19. 